\title{
Childhood socioeconomic status and risk in early family environments: predictors of global sleep quality in college students
}

\section{Authors: Cory J. Counts, Fiona C. Grubin, Neha A. John-Henderson}

NOTICE: this is the author's version of a work that was accepted for publication in Sleep Health Changes resulting from the publishing process, such as peer review, editing, corrections, structural formatting, and other quality control mechanisms may not be reflected in this document. Changes may have been made to this work since it was submitted for publication. A definitive version was subsequently published in Sleep Health, vol. 4, issue 3, June 2018, DOI\# 10.1016/ i.sleh.2018.02.003

Counts, Cory J. , Fiona C. Grubin, and Neha A. John-Henderson. "Childhood socioeconomic status and risk in early family environments: predictors of global sleep quality in college students." Sleep Health (March 2018). DOI: 10.1016/j.sleh.2018.02.003.

Made available through Montana State University's $\underline{\text { ScholarWorks }}$ scholarworks. montana.edu 


\title{
Childhood socioeconomic status and risk in early family environments: predictors of global sleep quality in college students
}

\author{
Cory J. Counts, Fiona C. Grubin, BS, Neha A. John-Henderson, PhD* \\ Montana State University, Department of Psychology, 319 Traphagen Hall, Bozeman, MT 59717, USA
}

\begin{abstract}
A B S T R A C T
Objective: Low socioeconomic status (SES) in childhood associates with poor sleep quality in adulthood. Separately, childhood family environments shape health into adulthood. Here, we investigated whether these early life factors independently or interactively inform global sleep quality in college students. Design: Cross-sectional.

Participants: College students at a state university $(\mathrm{N}=391)$.

Measurements: As a measure of childhood SES, we asked participants to consider their families' socioeconomic standing relative to the rest of the society during their childhood. We used the Risky Family questionnaire to measure adversity and the presence of warmth and affection in the family environment during childhood, and the Pittsburgh Sleep Quality Index as a measure of current global sleep quality. We used linear regressions adjusting for age and sex to examine relationships between childhood SES, risk in childhood family environments, and global sleep quality.

Results: Lower childhood SES and greater risk in childhood family environments independently predicted poor sleep quality. Importantly, in low-risk family environments, there was no significant difference in sleep quality as a function of childhood SES. However, students who were from low childhood SES backgrounds who also reported high levels of risk in their early family environments had the worst sleep quality. Conclusions: Findings highlight the importance of considering socioeconomic and family environments in childhood as informants of sleep quality across the lifespan. Compromised sleep quality in college students could affect academic performance and health over time.
\end{abstract}

A large body of research documents a graded relationship between socioeconomic status (SES) and health, such that individuals from low-SES backgrounds are worse off compared to their highSES counterparts. ${ }^{1,2}$ This relationship takes shape early in the lifespan, with economic disadvantage in childhood associating with poorer physical health across the lifespan and reduced life expectancy. ${ }^{3,4}$ These associations are largely independent of SES in adulthood. ${ }^{3}$ Children raised in low-SES environments are exposed to more physical and psychosocial stress compared to children raised in high-SES environments ${ }^{5,6}$ and are more likely to perceive ambiguous situations as a threat to their well-being. ${ }^{7,8}$

Separate from socioeconomic exposures, a growing body of literature documents an association between early life adversity and trauma with health across the lifespan. ${ }^{9,10}$ Importantly, recent investigations suggest that it is not only the presence of adversity or trauma in early environments which can shape health and health behaviors in enduring ways but also the dynamics of the early family environment. ${ }^{11}$ Family environments with high levels of conflict and low levels of warmth and affection can negatively impact adult health by shaping psychosocial functioning. ${ }^{12,13}$ These family environments are referred to as risky and associate with increased risk for ill health. ${ }^{11}$

Greater exposure to stress during the early years of a child's life may negatively impact the health behaviors that develop during this time, and these patterns may in turn persist into adulthood, partially explaining the enduring effect of early life experiences on health. ${ }^{14,15}$ For example, children raised in risky families are more likely to exhibit health-threatening behaviors including smoking, alcohol abuse, and drug abuse. ${ }^{11}$ Children who are exposed to stress may rely on these strategies to manage negative emotions or to cope in the absence of adequate emotion coping strategies. ${ }^{11}$ Sleep quality is one such behavioral pathway through which early life adversity and trauma are believed to negatively impact health. ${ }^{16,17}$

During childhood, socioeconomic adversity associates with compromised sleep quality, ${ }^{18,19}$ and low childhood SES predicts worse 
sleep quality in adulthood, independent of adult SES. ${ }^{20}$ Furthermore, previous research suggests that the relationship between low income and adverse health in adulthood is in part accounted for by compromised sleep quality. ${ }^{21,22}$ In a similar manner, early life adversity and trauma associate with compromised sleep quality across the lifespan. ${ }^{23,24}$ Specific to family environments, a prior investigation found that conflict in early life family environments associates with insomnia in adulthood. ${ }^{25}$

Multiple sources of early life environmental stress, such as low SES and a risky family environment, could have a cumulative negative effect on sleep. It remains unknown whether these independent dimensions of early life experience may interact to inform sleep quality, which is closely related to both physical and mental health. ${ }^{26,27}$

Although the majority of research focuses on the impact of childhood environments on sleep quality in adulthood, previous investigations provide evidence of an association between childhood adversity and compromised sleep quality in college students. ${ }^{24,28}$ More research in this area is needed given that the sleep quality of college students is particularly impaired. ${ }^{29,30}$ For many students, college is the first experience of living independently from their caregivers. As they work to adapt to their new surroundings, experiences, stresses, and challenges, their sleep quality is at a greater risk for disturbance. It is possible that early life experiences related to SES and family environments may inform quality of sleep during this time of adaptation, with college students who were raised in low-SES environments who also experienced a risky family life environment reporting the worst sleep quality. At the same time, the association between low childhood SES and compromised sleep quality in college could be weakened by a less risky family life environment during childhood. Prior research supports this line of reasoning, with findings indicating that maternal warmth moderates the association between low SES and an immune system inflammatory phenotype (a marker of disease risk). ${ }^{31}$ A separate investigation found that individuals reporting low levels of love and affection coupled with high levels of abuse in childhood had physiological profiles associated with high risk for disease in adulthood. ${ }^{32}$

The present study examines whether early life socioeconomic and family environments independently or interactively inform global sleep quality in college students. We predict that college students from low socioeconomic backgrounds who were also raised in risky family environments will report the lowest quality of sleep. This study extends prior research examining the relationships between adversity, SES, family environment, and sleep in important ways. First, prior investigations have largely focused on adversity, trauma, and conflict as shapers of sleep quality later in life. Here, we use a measure of early life environments which considers not only the presence of adversity or trauma but also the presence or absence of warmth and affection in the family environment. Furthermore, we consider the interaction between risk in early family environments and early SES. This is important because we are able to test whether a less risky family environment is capable of offsetting the previously observed relationship between low SES in childhood and low sleep quality later in life. ${ }^{20}$

\section{Methods}

Participants were students enrolled in introductory psychology courses at a large state university $(\mathrm{N}=391)$. As part of their coursework, students were asked to participate in research. Students who elected to participate in this research completed several healthand behavior-related questionnaires, and course credit was awarded upon completion of the questionnaire. No exclusionary criteria were used, and the study was made available to all students in the participant pool. All measures were approved by the university's institutional review board, and informed consent was obtained from all participants.

\section{Measures}

\section{Subjective childhood SES}

The MacArthur scale of subjective childhood SES is used to capture SES during childhood across objective SES indicators. Participants are presented with a 10-rung ladder and are asked to indicate where they feel their family stood during their childhood relative to other families in the United States. ${ }^{33,34}$ Scores ranged from 1 (lowest SES) to 9 (highest SES) $(M[S D]=6.42$ [1.75]). The question explains that the top of the ladder represents those families with more money, education, and better jobs, whereas the bottom of the ladder represents families who were worse off, had the least amount of money or education, and had jobs that are poorly respected or were unemployed.

\section{Subjective current SES}

The MacArthur scale of subjective SES is used to capture an individual's current SES across objective SES indicators. The same 10rung ladder described above is used, and participants were asked to place an " $\mathrm{X}$ " to indicate where they feel they currently stand relative to others in society with regard to occupation, money, and education $(M[\mathrm{SD}]=6.10[1.54]) .^{33}$

\section{Sleep quality}

The Pittsburgh Global Sleep Quality Index (PSQI) was used as a measure of participants' global sleep quality. ${ }^{35}$ The 19-item PSQI assesses sleep quality disturbances during the previous month. The scale consists of 19 items which were used to derive a total of 7 component scores: sleep quality, sleep latency, sleep duration, habitual sleep efficiency, sleep disturbances, sleep medication, and daytime dysfunction. The 7 component scores were summed to produce a global PSQI score. Global PSQI scores (with a possible range of 0-21; higher scores represent more severe sleep complaints) were computed for each participant $(M[S D]=6.58$ [3.21]). Internal consistency in this sample between the 7 component scores was $\alpha=.75$.

\section{Risky family environments}

The Risky Families questionnaire was used to assess participants' exposure to physical, mental, and emotional neglect or abuse during their adolescent and childhood years in addition to the presence or absence of warmth and affection. ${ }^{36}$ Participants indicate how frequently certain events or situations occurred in their homes during the ages of 5-15 years using a 5-point Likert scale ( $1=$ not at all and $5=$ very often). Example questions from this measure include "How often did a parent or other adult in the household make you feel that you were loved, supported, and cared for?" and "How often would you say there was quarreling, arguing, or shouting between your parents?" Items measuring the presence of positive qualities in the family environment are reverse scored, and all 10 items are summed to capture the overall level risk in the early family environment.

\section{Depressive symptoms}

We used Beck's Depression Inventory (BDI-II) as a measure of current depressive symptoms. The BDI-II is a 21-item questionnaire widely used to assess subclinical and clinical depression. ${ }^{37}$ Each item includes 4 response options. As an example, participants are 
asked to select which of the following 4 statements most accurately reflects how they are have been feeling in the last 2 weeks, including today: (0) I am not particularly discouraged about the future, (1) I feel discouraged about the future, (2) I feel I have nothing to look forward to, and (3) I feel the future is hopeless and that things cannot improve. A total score is calculated by summing all of the responses, and higher scores reflect more depressive symptoms.

\section{Positive and negative affect}

Participants reported how much they had experienced negative and positive affect over the course of the past week, including today, using 20 items (eg, enthusiastic, hostile, irritable, inspired) on the Positive and Negative Affect Schedule (PANAS) ranging from 1 (never) to 5 (always). ${ }^{38}$

\section{Alcohol use and smoking status}

As measures of alcohol use and current smoking status, participants responded to the following questions with a yes or no: Do you drink alcoholic beverages regularly? Do you smoke any tobacco products regularly?

\section{Data analysis}

Analyses were conducted using SPSS (version 24; IBM, Armonk, $\mathrm{NY}$ ). Linear regression models were used to conduct the main analyses. Continuous covariates were centered prior to use in statistical models. In all reported linear regression models, age and sex are included as covariates. We first examined the relationships between subjective childhood SES and global sleep quality and the relationship between risky family environments and global sleep quality. Next, to test our hypothesis, we created an interaction term between subjective childhood SES and risk in early family environments, and examined whether this interaction term predicted global sleep quality. In subsequent analyses, we expand our model to include current subjective SES, depressive symptoms, positive and negative affect, alcohol use, and current smoking status.

\section{Results}

Descriptive statistics are listed in Table 1, and bivariate correlations between measures of SES and main variables of interest are listed in Table 2 . The sample was $87.5 \%$ White, $4.6 \%$ mixed race, 2.8\% American Indian/Alaska Native, 2.1\% Hispanic/Latino/Chicano, $1.5 \%$ Asian, $2.0 \%$ other, and .3\% African American. Of note, the mean sleep quality in this sample of college students was slightly above the threshold for poor sleep quality according to the PSQI cut-off point $>5 .^{27}$

Table 1

Descriptive statistics

\begin{tabular}{lllll}
\hline & $\mathrm{n}$ & $M(\mathrm{SD})$ & $\%(\mathrm{n})$ & Range \\
\hline Race (\% White) & 392 & & $87.1(344)$ & \\
Sex (\% female) & 392 & & $65.1(257)$ & \\
Age & 376 & $19.57(3.22)$ & & $18-52$ \\
Subjective childhood SES & 384 & $6.42(1.75)$ & & $1-10$ \\
Subjective current SES & 376 & $6.10(1.54)$ & & $2-10$ \\
Global sleep quality & 380 & $6.58(3.21)$ & & $0-18$ \\
Depressive symptoms (BDI) & 380 & $15.34(5.04)$ & & $0-27$ \\
Positive affect (PANAS) & 379 & $32.83(7.95)$ & & $10-50$ \\
Negative affect (PANAS) & 380 & $22.91(7.56)$ & & $10-50$ \\
Regular alcohol users & 167 & & & $43 \%$ \\
Current tobacco users & 26 & & & $6.75 \%$ \\
\hline
\end{tabular}

Table 2

Bivariate correlations of SES measures with variables of interest

\begin{tabular}{lccc}
\hline & Subjective & & Subjective \\
\cline { 2 - 2 } & Childhood SES & & Current SES \\
\hline Age & -0.62 & -.04 \\
Sex $(1=$ male, $2=$ female) & $-0.13^{*}$ & $-0.11^{*}$ \\
Subjective childhood SES & 1.0 & $0.52^{* *}$ \\
Subjective current SES & $0.52^{* *}$ & 1.0 \\
Objective current SES & $0.55^{*}$ & $0.27^{* *}$ \\
Global sleep quality & $-0.23^{* *}$ & $-0.21^{* *}$ \\
Risk in family environment & -0.003 & -.04 \\
Current depressive symptoms (BDI) & -.08 & -.02 \\
Positive affect (PANAS) & $.22^{* *}$ & $.20^{* *}$ \\
Negative affect (PANAS) & $-.17^{* *}$ & -.08 \\
Alcohol use (1 = regular user) & .05 & .01 \\
Tobacco use $(1=$ current user) & -.01 & -.01 \\
\hline$* P<.05$. & & \\
$* * * .001$. & &
\end{tabular}

\section{Childhood SES and global sleep quality}

Controlling for age and sex, subjective childhood SES was associated with poorer global sleep quality $(\beta=-0.30 t[365]=-5.75$, $P<.001, R^{2}$ change $=0.08$ ).

\section{Risky family environments and sleep quality}

As predicted, adjusting for age and sex, growing up in a risky family was associated with poor sleep quality $(\beta=0.41, t[360]=$ $8.63, P<.001, R^{2}$ change $\left.=0.17\right)$.

\section{Subjective childhood SES by risky family environment predicting sleep quality}

To test our prediction that childhood SES would interact with risk in early family environments to predict global sleep quality, we entered the subjective childhood SES measure, the risky family measure, their interaction term, and the covariates of age and sex into a linear regression model. In line with our hypothesis, there was a significant interaction between risky family environments and childhood SES in predicting global sleep quality $(\beta=-0.12$, $t[356]=-2.58, P=.01, R^{2}$ change $=0.02$ ). The pattern of this interaction is displayed in Figure 1. To further probe the reported interaction, we conducted simple slopes analyses. Greater risk in family environment was associated with lower sleep quality for individuals from both low (1 SD below mean) and high (1 SD above mean) childhood SES $(b=1.65, t[359]=6.42, P<.001$ and $b=0.79, t[359]=$ $2.83, P=.01$, respectively). In less risky family environments (1 SD below mean), childhood SES was not associated with global sleep quality $(b=-0.17, t[359]=-0.59, P=.56)$. However in highrisk family environments (1 SD above mean), childhood SES was associated with sleep quality such that individuals who were also from low childhood SES backgrounds had significantly worse sleep compared to those individuals from high childhood SES backgrounds $(b=-1.03, t[359]=-4.07, P<.001)$.

In a separate linear regression model, we added covariates to examine whether the observed relationships exist above and beyond the effects of current SES, depressive symptoms, current mood, and health behaviors, all of which are factors that are known to associate with sleep quality. ${ }^{39-42}$ In this model, in addition to age and sex, we added the covariates of current subjective SES, depressive symptoms (BDI total score excluding sleep item), positive and negative affect, alcohol use, and smoking status to see if the previously observed interaction persisted. With the addition of these covariates, the interaction between childhood SES and early family environments remained 


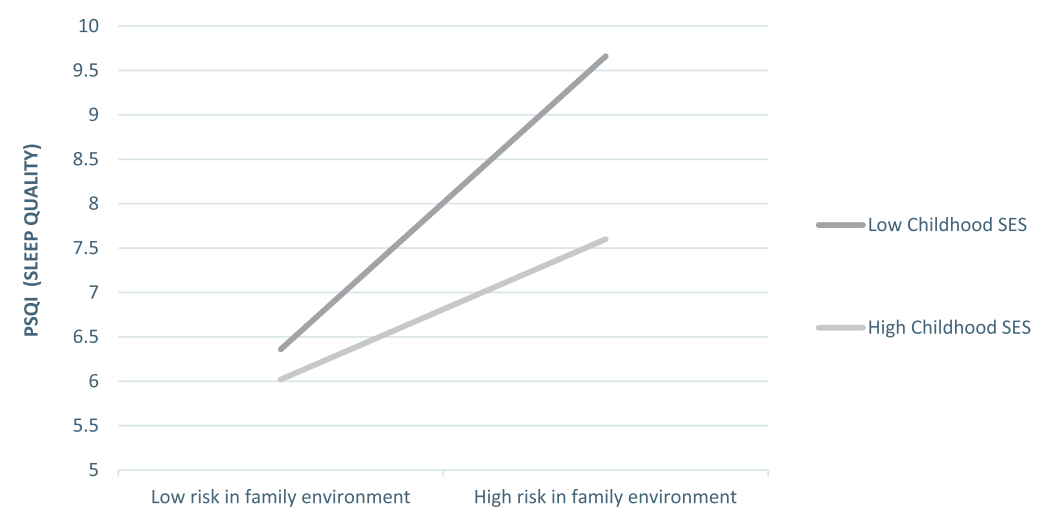

Fig. 1. PSQI global sleep quality as a function of degree of risk in early family environment and subjective childhood SES. Results from a linear regression analysis controlling for age and sex.

significant as a predictor of global sleep quality in this sample of college students, $\left(\beta=-0.10, t[337]=-2.09, P=.04, R^{2}\right.$ change $=$ 0.01).

\section{Discussion}

Our findings revealed an inverse relationship between sleep quality and subjective childhood SES. Lower SES during childhood associated with worse sleep quality among college students. In addition, the data revealed a relationship between early life risk in family environments, with greater risk associating with worse sleep quality. However, as predicted, the association between childhood SES and sleep quality was moderated by early life family dynamics. Participants who reported low childhood SES in addition to a risky family environment reported the worst sleep quality as college students, whereas students who grew up in a low-SES environment who experienced a less risky, more nurturing family environment reported significantly better sleep quality as college students. Students who reported high childhood SES and a risky family environment also had significantly worse sleep quality compared to their peers from similar childhood SES backgrounds who experienced a less risky family environment. The pattern of these findings highlights the important role of the childhood family environment as a moderator of the relationship between childhood SES and sleep quality later in life.

Furthermore, our findings persisted with the inclusion of several covariates that are associated with sleep. The PSQI measure of global sleep quality associates with depressive symptoms. ${ }^{43}$ As such, we considered the possibility that childhood SES and early family environments were predicting depressive symptoms and not necessarily sleep problems. In this sample, although the PSQI sleep quality measure was significantly associated with depressive symptoms, inclusion of depressive symptoms as a covariate did not affect our findings. In addition, we included current subjective SES, affect (positive and negative), alcohol use, and smoking status as covariates given their documented association with sleep, ${ }^{39-42}$ and the reported findings were not affected.

Growing up in a low-SES environment may be stressful for many reasons. Low SES associates with greater exposure to both physical and psychological stressors. ${ }^{44,45}$ For example, low-SES environments are likely to have more noise, pollution, crime, and physical crowding than high-SES environments. ${ }^{45,46}$ In addition, low-SES environments are linked to more psychosocial stressors (eg, less control, unpredictability, lack of financial stability) and fewer resources to manage these stressors. ${ }^{44}$ This greater load of both physical and psychosocial stress is believed to be an important explanatory factor in the relationship between low SES and poor health outcomes. ${ }^{45}$

Previous research indicates that stress exposures early in the lifespan can sensitize individuals to stress experienced later in life. ${ }^{47-50}$ As such, the college experience, which presents new stressors and challenges for most students, may be particularly stressful for individuals raised in low-SES environments. Our findings indicate that the relationship between childhood SES and an important health behavior, sleep, is moderated by early life family dynamics and, furthermore, that early family environments affect sleep quality for college students from both high and low childhood SES backgrounds. This makes sense given the robust literature documenting the enduring negative effects of being raised in a risky family environment on social relationships, hostility, and reactivity in response to conflict. ${ }^{11,12}$ As noted previously, the observed interaction between childhood SES and childhood family environments is in line with previous research indicating that family dynamics can moderate the association between childhood SES and health-relevant outcomes. ${ }^{31,32}$

There are important limitations to note. First, this work is crosssectional, and thus, causality cannot be inferred. Second, we did not have an objective measure of childhood SES. The MacArthur ladder measure of childhood SES used in this research asks individuals to consider where their family stood during childhood compared to other families with regard to parental occupation, income, and education. Accumulating evidence suggests that subjective measures of childhood SES are more closely associated with outcomes later in life than objective measures of childhood SES. ${ }^{51,52}$ Advantages of subjective measures of childhood SES include allowance for consideration of several indicators of SES and their ability to capture important subtleties such as prestige of college their parents attended or family wealth which may not be apparent in reports of parental income. Finally, with regard to limitations regarding the childhood SES measure, it is important to note that the means for current SES and childhood SES are fairly similar. This raises the possibility that one's current SES biases one's view of their past SES. In an effort to address this limitation, we included current SES as a covariate in our analyses.

Second, although the PSQI is weakly associated with objective measures of sleep (eg, polysomnography and actigraphy), ${ }^{53,54}$ it is related to unique psychological and biological correlates ${ }^{55-57}$ and perhaps is more closely related to the psychological correlates of sleep disturbances than objective measures of sleep. ${ }^{58}$ Future research should examine whether childhood SES and early life family environments would similarly inform objective measures of sleep quality (eg, polysomnography). 
In addition, it is important to note that the sample was $87 \%$ White, which limits generalizability of these findings to all college students. It remains possible that the pattern of results could differ by ethnicity or race, and this possibility should be examined in future research. Furthermore, although our lack of exclusionary criteria can be viewed as a strength in that it allowed for a broad sample, it is possible that participants were taking medications that could affect their sleep. Importantly the PSQI measure of global sleep quality includes a question to assess how often individuals are taking medication to help them sleep; however, it remains possible that medications taken for other purposes could affect their sleep. Lastly, variability in SES in a college sample is less compared to the general population.

Finally, given our reliance on retrospective self-report for our predictors, it is possible that the accuracy of individuals' memory of their early life environments may be negatively affected by time, and this effect may be particularly strong for older participants. Furthermore, an individual's self-esteem may influence their report of these variables. We are unable to account for this possibility because this research did not include a measure of self-esteem, and this factor should be considered in future research.

In summary, our findings highlight the potential for a positive family environment in childhood to offset the previously observed association between low childhood SES and poor sleep quality later in life. They also draw attention to the increased vulnerability to poor sleep quality for those individuals who have both low childhood SES and a risky family environment in childhood. In general, college students report low sleep quality, but our work suggests that early life experiences (both socioeconomic and familial) are important predictors of sleep quality for this population. Sleep quality has both direct and indirect effects on college students' academic performance and physical and psychological health. ${ }^{55}$ The compromised sleep quality observed for college students who experienced risky family environments in childhood may negatively affect their social relationships and academic performance, and these effects may be most pronounced for those students who were also raised in a low-SES environment. If these patterns persist, the psychological and physical health of these students may suffer. Future research should extend upon these findings by examining differences in stress exposure, coping, and health behaviors that may explain the association between early life factors and sleep quality observed here.

\section{Conflicts of interest}

The authors have no conflicts of interest to disclose.

\section{References}

1. Adler NE, Stewart J. Preface to the biology of disadvantage: socioeconomic status and health. Ann N Y Acad Sci. 2010;1186(1):1-4

2. Schulz AJ, Mentz G, Lachance L, Johnson J, Gaines C, Israel B. Associations between socioeconomic status and allostatic load: effects of neighborhood poverty and tests of mediating pathways. Am J Public Health. 2012;102(9):1706-1714.

3. Galobardes B, Lynch JW, Smith GD. Childhood socioeconomic circumstances and cause-specific mortality in adulthood: systematic review and interpretation. Epidemiol Rev. 2004;26:7-21. https://doi.org/10.1093/epirev/mxh008.

4. Kittleson MM, Meoni LA, Wang NY, Chu AY, Ford DE, Klag MJ. Association of childhood socioeconomic status with subsequent coronary heart disease in physicians. Arch Intern Med. 2006;166:2356-2361.

5. Chen E. Why socioeconomic status affects the health of children. Curr Dir Psychol Sci. 2004;13(3):112-115.

6. Chen E, Martin A, Matthews K. Trajectories of socioeconomic status across children's lifetime predict health. Pediatrics. 2007;120(2):297-303.

7. Ross C, Mirowsky J, Pribesh S. Powerlessness and the amplification of threat: neighborhood disadvantage, disorder, and mistrust. Am Sociol Rev. 2001;66(4): 568-591.

8. Chen E, Matthews K, Zhou F. Interpretations of ambiguous social situations and cardiovascular responses in adolescents. Ann Behav Med. 2007;34(1):26-36.

9. Friedman EM, Karlamangla AS, Gruenwald T, Koretz B, Seeman TE. Early life adversity and adult biological risk profiles. Psychosom Med. 2015;77(2):176-185.
10. Mock SE, Arai SM. Childhood trauma and chronic illness in adulthood: mental health and socioeconomic status as explanatory factors and buffers. Front Psychol. 2010;1:246.

11. Repetti RL, Taylor SE, Seeman TE. Risky families: family social environment and the mental and physical health of offspring. Psychol Bull. 2002;128:330-336.

12. Taylor SE, Lerner JS, Sage RM, Lehman BJ, Seeman TE. Early environment, emotions, responses to stress, and health. J Pers. 2004;72:1365-1393.

13. Loucks EB, Almeida ND, Taylor SE, Matthews KA. Childhood family psychosocial environment and coronary heart disease risk. Psychosom Med. 2011;73(7):563-571.

14. Doom J, Mason S, Suglia S, Clark C. Pathways between childhood/adolescent adversity, adolescent socioeconomic status, and long term cardiovascular disease risk in young adulthood. Soc Sci Med. 2017;188:166.

15. Mcphie M, Weiss JA, Wekerle C. Psychological distress as a mediator of the relationship between childhood maltreatment and sleep quality in adolescence: results from the Maltreatment and Adolescent Pathways (MAP) longitudinal study. Child Abuse Negl. 2014;38:2044-2052.

16. Koskenvuo K, Hublin C, Partinen M, Paunio T, Koskenvuo M. Childhood adversities and quality of sleep in adulthood: a population based study of 26,000 Finns. Sleep Med. 2010;11:17-22.

17. Wang Y, Raffekd MR, Slopen N, Hale L, Dunn EC. Childhood adversity and insomnia in adolescence. Sleep Med. 2016;21:12-18.

18. Larson K, Russ SA, Crall JJ, Halfon N. Influence of multiple social risks on children's health. J Pediatr. 2008;121(2):337-344.

19. El-Sheikh M, Bagley EJ, Keiley M, Elmore-Staton L, Chen E, Buckhalt JA. Economic adversity and children's sleep problems: multiple indicators and moderation of effects. Health Psychol. 2013;32(8):849-859.

20. Tomfohr L, Ancoli-Israel S, Dimsdale J. Childhood socioeconomic status and race are associated with adult sleep. Behav Sleep Med. 2010;8(4):219-230.

21. Moore PJ, Adler NE, Williams DR, Jackson JS. Socioeconomic status and health: the role of sleep. Psychosom Med. 2002;64(2):337-344.

22. Stringhini S, Haba-Rubio J, Marques-Vidal P, Waeber G, Preisig M, Guessous I, Heinzer R. Association of socioeconomic status with sleep disturbances in the Swiss population-based CoLaus study. Sleep Med. 2015;16(4):469-476.

23. Kajeepeta S, Gelaye B, Jackson CL, Williams MA. Adverse childhood experiences are associated with adult sleep disorders: a systematic review. Sleep Med. 2015; 16(3):320-330.

24. Ramsawh HJ, Ancoli-Israel S, Sullivan SG, Hitchcock CA, Stein MB. Neuroticism mediates the relationship between childhood adversity and sleep quality. Behav Sleep Med. 2011;9(3):130-143.

25. Gregory AM, Caspi A, Moffitt TE, Poulton R. Family conflict in childhood: a predictor of later insomnia. Sleep. 2006;29(8):1063-1067.

26. Friedman E. Sleep quality, social well-being, gender, and inflammation: an integrative analysis in a national sample. Ann N Y Acad Sci. 2011;12311(1):23-34.

27. Hoyt MA, Bower JE, Irwin MR, Weierich MR, Stanton AL. Sleep quality and depressive symptoms after prostate cancer: the mechanistic role of cortisol. Behav Neurosci. 2016;130(3):351-356.

28. Gress-Smith JL, Roubinov DS, Andreotti C, Compas BE, Luecken LJ. Prevalence, severity and risk factors for depressive symptoms and insomnia in college undergraduates. Stress Health. 2013;1:63-70.

29. Prichard J, Cunningham J. Academic stress, social trauma, and disturbed sleep in a large population of college students: interconnections and implications. J Adolesc Health. 2012;50(2):32.

30. Lund HG, Reider BD, Whiting AB, Prichard J. Sleep patterns and predictors of disturbed sleep in a large population of college students. J Adolesc Health. 2010;46 (2):124-132.

31. Chen E, Miller GE, Kobor MS, Cole SW. Maternal warmth buffers the effects of low early-life socioeconomic status on pro-inflammatory signaling in adulthood. Mol Psychiatry. 2011;16(7):729-737.

32. Carroll JE, Gruenewald TL, Taylor SE, Janicki-Deverts D, Matthews KA, Seeman TE. Childhood abuse, parental warmth, and adult multisystem biological risk in the coronary artery risk development in young adults study. Proc Natl Acad Sci U S A. 2013;110(42):17149-17153.

33. Adler NE, Epel ES, Castellazo G, Ickovics JR. Relationship of subjective and objective social status with psychological and physiological functioning: preliminary data in healthy, White women. Health Psychol. 2000;19:586-592.

34. Gianaros PJ, Horenstein JA, Hariri AR, Sheu LK, Manuck SB, Matthews KA, Cohen S. Potential neural embedding of parental social standing. Soc Cogn Affect Neurosci. 2008;3:91-96.

35. Buysse DJ, Reynolds CF, Monk TH, Berman SR, Kupfer DJ. The Pittsburgh Sleep Quality Index (PSQI): a new instrument for psychiatric research and practice. Psychiatry Res. 1989;28(2):193-213.

36. Felitti VJ, Anda RF, Nordenberg D, Williamson DF, Spitz AM, Edwards V, Koss MP, Marks JS. Relationship of childhood abuse and household dysfunction to many of the leading causes of death in adults. The Adverse Childhood Experiences (ACE) study. Am J Prev Med. 1998;14(4):245-258.

37. Beck AT, Ward CH, Mendelson M, Mock J, Erbaugh J. An inventory for measuring depression. Arch Gen Psychiatry. 1961;4:561-571.

38. Watson D, Clark LA, Tellegen A. Development and validation of brief measures of positive and negative affect: the PANAS scales. J Pers Soc Psychol. 1988;54:1063-1070.

39. Friedman EM, Love GD, Rosenkranz MA, Urry HL, Davidson RJ, Singer BH, Ryff CD. Socioeconomic status predicts objective and subjective sleep quality in aging women. Psychosom Med. 2007;69(7):682-691.

40. Blaxton JM, Bergman CS, Whitehead BR, Braun ME, Payne JD. Relationships among nightly sleep quality, daily stress and daily affect. J Gerontol B Psychol Sci Soc Sci. 2017;72(3):363-372. 
41. Ogeil RP, Phillips JG, Rajaratnam SMW, Broadbear JH. Risky drug use and effects on sleep quality and daytime sleepiness. Hum Psychopharmacol Clin Exp. 2015;30(5): 356-363.

42. Valerio TD, Kim MJ, Sexton-Radek K. Association of stress, general health, and alcohol use with poor sleep quality among U.S. college students. Am J Health Educ. 2016;47(1):17-23.

43. Seidel S, Dal-Bianco P, Eleonore P, Muller N, Schadenhofer C, Lamm C, Leherner J. Depressive symptoms are the main predictor for subjective sleep quality in patients with mild cognitive impairments-a controlled study. PLoS One. 2015. https://doi.org/10.1371/journal.pone.0128139.

44. Baum A, Garofalo JP, Yali AM. Socioeconomic status and chronic stress: does stress account for SES effects on health? In: Adler NE, Marmot M, McEwen BS, Stewart J, editors. Socioeconomic status and health in industrial nations: social, psychological, and biological pathways; socioeconomic status and health in industrial nations: social, psychological, and biological pathways. New York, NY: New York Academy of Sciences; 1999. p. 131-144.

45. Sapolsky RM. Sick of poverty. Sci Am. 2005;293(6):92-99.

46. Dale LM, Goudreau S, Perron S, Ragettli MS, Hatzopoulou M, Smargiassi A. Socioeconomic status and environmental noise exposure in Montreal, Canada. BMC Public Health. 2015;15:205.

47. Heim C, Newport DJ, Heit S, Graham YP, Wilcox M, Bonsall R, Miller AH, Nemeroff CB. Pituitary-adrenal and autonomic responses to stress in women after sexual and physical abuse in childhood. JAMA. 2000;284:592-597.

48. Heim C, Newport DJ, Wagner D, Wilcox MM, Miller AH, Nemeroff CB. The role of early adverse experience and adulthood stress in the prediction of neuroendocrine stress reactivity in women: a multiple regression analyses. Depress Anxiety. 2002;15(3):117-125.
49. Tyrka AR, Wier L, Price LH, Ross N, Anderson GM, Wilkinson CW, Carpenter LL Childhood parental loss and adult hypothalamic-pituitary-adrenal functioning. Biol Psychiatry. 2008;63:1147-1154.

50. Carpenter LL, Shattuck TT, Tyrka AR, Geracioti TD, Price LH. Effect of childhood physical abuse on cortisol stress response. Psychopharmacology. 2011;214(1):367-375.

51. John-Henderson N, Stellar JE, Mendoza-Denton R, Francis DD. Socioeconomic status and social support: social support reduces inflammatory reactivity for individuals whose early-life socioeconomic status was low. Psychol Sci. 2015;26(10):1620-1629.

52. Kraus MW, Adler N, Chen TD. Is the association of subjective SES and self-rated health confounded by negative mood? An experimental approach. Health Psychol. 2013;32(2):138-145.

53. Grandner MA, Kripke DF, Yoon IY, Youngstedt SD. Criterion validity of the Pittsburgh Sleep Quality Index: investigation in a non-clinical sample. Sleep Biol Rhythms. 2006;4:129-139.

54. Landry GJ, Best JR, Liu-Ambrose T. Measuring sleep quality in older adults: a comparison using subjective and objective methods. Front Aging Neurosci. 2015;7:166.

55. Casement MD, Harrington KM, Miller MW, Resick PA. Associations between Pittsburgh sleep quality index factors and health outcomes in women with posttraumatic stress disorder. Sleep Med. 2012;13(6):752-758.

56. Wong ML, Lau EYY, Wan JHY, Cheung SF, Hui CH, Mok DSY. The interplay between sleep and mood in predicting academic functioning, physical health and psychological health: a longitudinal study. J Psychosom Res. 2013;74(4):271-277.

57. Jackowska M, Ronaldson A, Brown J, Steptoe A. Biological and psychological correlates of self-reported and objective sleep measures. J Psychosom Res. 2016;84:52-55.

58. Klumpp H, Roberts J, Kapella MC, Kennedy AE, Kumar A, Phan KL. Subjective and objective sleep quality modulate emotion regulatory brain function in anxiety and depression. Depress Anxiety. 2017;34:651-656. 